\title{
Characteristics of Diurnal Pulses Observed in Typhoon Atsani Using Retrieved Cloud Property Data
}

\author{
Xinyue Wang, Hironobu Iwabuchi, and Naoya Takahashi \\ Center for Atmospheric and Oceanic Studies, Graduate School of Science, Tohoku University, Sendai, Japan
}

\begin{abstract}
Using several cloud properties retrieved from the Himawari-8 satellite, combined with the best track storm center information, the temporal-spatial features of tropical cyclone (TC) diurnal pulses in 2015 Super Typhoon Atsani (T1516) are coherently depicted. To demonstrate the radially outward transition processes of the diurnal pulses from one cloud type to another, we divided high clouds into three types: opaque high cloud (OHC), cirrostratus (Cs), and cirrus (Ci). Two alternatively appeared peaks in cloud top height $(\mathrm{CTH})$ within the storm central area and their corresponding outward pulses are identified. The first pulse covers a 24-hour period, it starts at $\sim 0500-0700$ local solar time (LST), with a gradual transition from $\mathrm{OHC}$ to $\mathrm{Cs}$, then ends in $\mathrm{Ci}$ at around $0400 \mathrm{LST}$. The second pulse lasts for half a day and limited within $1000 \mathrm{~km}$ from the storm center. When the first CTH pulse ends in $\mathrm{OHC}, \mathrm{Cs}$, and $\mathrm{Ci}$, their cloud fractional coverage and the outward expansion of large cloud optical thickness also reach maximum accordingly.
\end{abstract}

(Citation: Wang, X., H. Iwabuchi, and N. Takahashi, 2019: Characteristics of diurnal pulses observed in Typhoon Atsani using retrieved cloud property data. SOLA, 15, 137-142, doi:10.2151/ sola.2019-025.)

\section{Introduction}

The diurnal cycle has long been recognized as a typical characteristic of organized tropical deep convection (Kraus 1963; Randall 1991; Chen and Houze 1997), evident in both cloud outflow (Kossin 2002) and precipitation (Bowman and Fowler 2015). Until recent years, the "diurnal pulse" concept was proposed to describe a powerful propagating feature of this cycle (Bain et al. 2010; Dunion et al. 2014). A diurnal pulse starts from the inner $\sim 150 \mathrm{~km}$ of a storm, and moves radially outward to several hundreds of kilometers away from the storm center. This cyclical process might be an important feature of tropical cyclone (TC) dynamics and could be related to TC structural change (Holland and Merrill 1984; Dunion et al. 2014).

Previous studies have extensively explored the temporal evolution of cloudiness by utilizing infrared (IR) satellite imagery obtained from geostationary satellite (Browner et al. 1977; Muramatsu 1983; Lajoie and Butterworth 1984). Those studies revealed that the horizontal areal extent of cirrus canopy oscillates strongly with a period of 24-hour, reaching its maximum at solar noon. This diurnal cycle is possibly driven by incoming solar radiation (Wu and Ruan 2016). The cirrus coverage was also found to be inversely proportional to storm intensity (Browner et al. 1977).

The satellite IR brightness temperature has been commonly used as a proxy for the cloud-top height (CTH, Haffke et al. 2015; $\mathrm{Wu}$ et al. 2016). Originally, the cyclical pattern of the CTH was assumed to be forced by a diurnal oscillation (Muramatsu, 1983). However, a semidiurnal oscillation theory has been recently proposed and widely accepted as the current consensus. Bain et al. (2010) listed some of the key results from several studies that have estimated the amplitude and phase of the cycle, in both

Corresponding author: Hironobu Iwabuchi, Center for Atmospheric and Oceanic Studies, Graduate School of Science, Tohoku University, 6-3 Aoba, Aramakiaza, Aoba-ku, Sendai, Miyagi 980-8578, Japan. E-mail: hiroiwa@tohoku.ac.jp.

(C) The Author(s) 2019. This is an open access article published by the Meteorological Society of Japan under a Creative Common Attribution 4.0 International (CC BY 4.0) license (http://creativecommons.org/license/by/4.0).

\section{Data and study method}

cloud and precipitation. An early morning peak and an afternoon maximum are identified as the starting points of semidiurnal pulses. In general, the morning peak dominates and the convective system strengthens in the early morning by various mechanisms. In remote oceanic regions such as in the case of typhoon Atsani, direct radiation-convection effect (i.e., lapse rate effect) may be the most important cause for the observed morning peak (Chen and Houze 1997).

Using only the evolution in brightness temperature may not be sufficient to capture the temporal and spatial variation of cloud types other than opaque high cloud. Iwabuchi et al. (2018) developed an algorithm named Integrated Cloud Analysis System (ICAS) that retrieves cloud properties from the measurements of eight infrared bands of geostationary satellite Himawari-8. ICAS method well captures the diurnal cycles of clouds in a consistent way regardless of solar zenith angle. In the present study, we have applied the ICAS to the frequent observations made by Himawari-8, enabling an accurate identification of various cloud types. Therefore, the temporal and spatial evolution, and the life cycle from generation to dissipation of these clouds can be studied more thoroughly.

By utilizing a combination of $\mathrm{CTH}$ and cloud optical thickness (COT), this study attempts to present two pulse processes that alternatively appeared in the daily CTH field of Typhoon Atsani. We also show a consecutive transition of cloud optical thickness in the radially outward propagating pulses. Section 2 introduces the data set retrieved by ICAS, Section 3 describes the results, and Section 4 presents our conclusions.

In this study, IR satellite-derived cloud properties, such as COT and CTH, were retrieved using the ICAS algorithm (Iwabuchi et al. 2016, 2018). The main data used for cloud retrieval were obtained from the Advanced Himawari Imager (AHI) onboard the Himawari-8 satellite, with a 2-km spatial resolution at the sub-satellite point (nadir) (Bessho et al. 2016). Eight IR bands including atmospheric window bands, water vapor, and carbon dioxide absorption bands were used. In the retrieval algorithm, land surface emissivity, and land and ocean surface temperatures were also utilized. The atmospheric profiles of parameters such as humidity, temperature, and ozone concentration were interpolated temporally and spatially from the Modern-Era Retrospective Analysis for Research and Application, Version-2 (MERRA-2) meteorological field product (Gelaro et al. 2017). The retrievals of cloud properties were formulated based on an optimal estimation approach (Rodgers 2000). For more detailed information on the ICAS retrieval, see Iwabuchi et al. (2016), Iwabuchi et al. (2018), and Khatri et al. (2018).

Given the tempo-spatial scope of Typhoon Atsani's life cycle, we selected ten days spanning from 0000 LST 15 August to 2400 LST 24 August 2015, and a region covering $130^{\circ} \mathrm{E}-220^{\circ} \mathrm{E}$, $3^{\circ} \mathrm{N}-46^{\circ} \mathrm{N}$ for our study. During that study period, the max wind of Atsani increased from $35 \mathrm{kt}$ to $100 \mathrm{kt}$, and then decreased to $60 \mathrm{kt}$. The retrieved satellite data used for this analysis have a temporal resolution of $30 \mathrm{~min}$. Note that there was no observation at 2330 UTC on 17 August, we hence excluded the data at that time. Best-track data for Atsani were obtained from the Japan Meteorological Agency. Six-hourly measurements at 0000, 0600, 1200 , and 1800 UTC include the TC configuration information, 
such as the location and intensity. The best-track data were further interpolated to match the temporal resolution of the retrieved satellite data. Then the cloud analyses are conducted using azimuthally-averaged calculations centered on the best-track center.

For the cloud fractional coverage analysis, high clouds with tops above $10 \mathrm{~km}$ were analyzed. Following Iwabuchi et al. (2018), COT values of 1 and 6 were selected as boundaries for separating the clouds into cirrus, cirrostratus, and opaque high clouds. We defined a storm-centered disk with a radius of $1500 \mathrm{~km}$ that is divided into thirty annuli, each with a radial width of $50 \mathrm{~km}$. The cloud fraction and CTH and COT medians were computed at each annulus, for each local time bin with a $30-\mathrm{min}$ resolution. Before generating the time-distance bins, the time for each pixel has been corrected from UTC to Local Solar Time (LST).
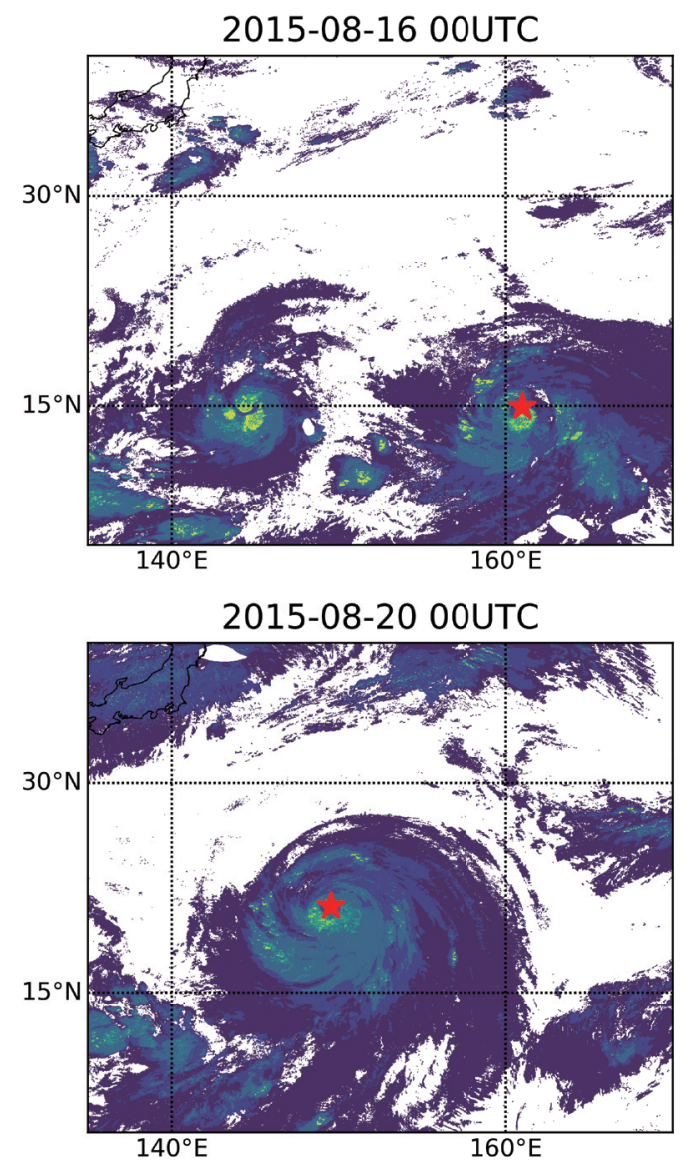

2015-08-24 00UTC

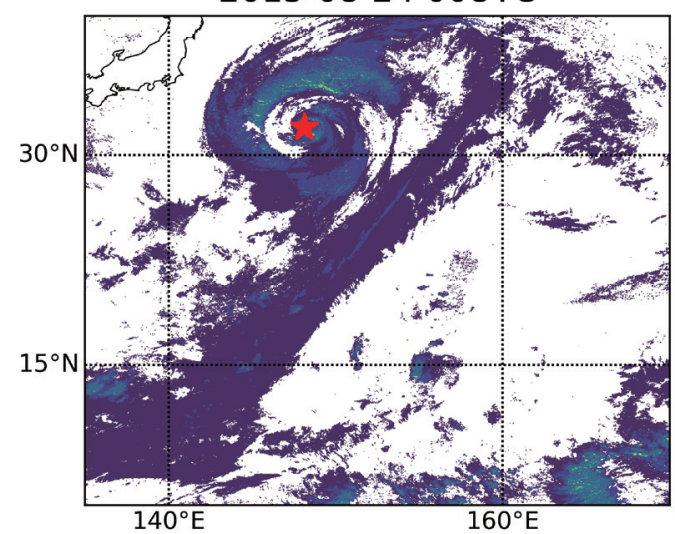

\section{Results}

In August 2015, two typhoons appeared over the western Pacific at the same time. Atsani, the stronger one, was graded as a Tropical Strom on 15 August with a maximum wind speed of $35 \mathrm{kt}$, then reached super typhoon intensity from 19 August 0000 UTC to 20 August 0000 UTC with a maximum sustained wind speed of $100 \mathrm{kt}$ and a minimum central pressure of $925 \mathrm{hPa}$, over the open water in the Pacific. It turned northwestward around Chichijima island, and finally weakened from a Severe Tropical Storm to an extra-tropical cyclone on 25 August. The life cycle of Atsani is depicted with the spatial evolution of high cloud COT at 2-day intervals (Fig. 1). The same developing process captured by Himawari-8 is shown in Fig. S1. That set of pseudocolor images
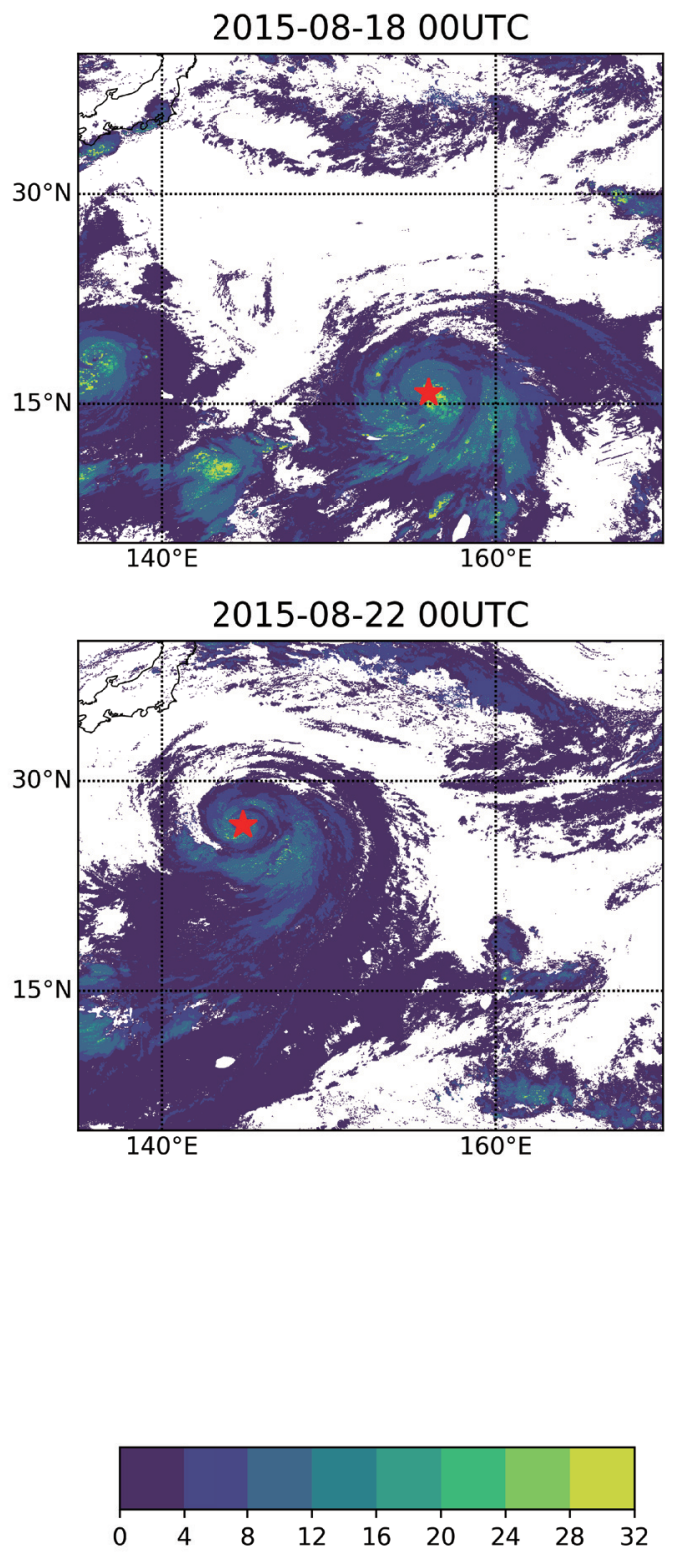

Fig. 1. Life cycle of the TC Atsani at a two-day interval from 16 to 24 August 2015, depicted by the spatial evolution of high cloud COT retrieved by ICAS with Himawari- 8 observation. The red star indicates the best track of the storm center. 
was created by using the AHI bands 15,11 , and 16 as red, green, and blue channels, respectively.

We first analyze the evolution of the COT field to gain an overview of the outward expansion of clouds inside TC Atsani. Figure 2 presents the 10-day variation of median $\log (\mathrm{COT})$ in each storm-centered annulus within $1500 \mathrm{~km}$ from the storm center, from 0000 LST 15 August to 2400 LST 24 August. The outward expansion of thick clouds, along with a gradual decrease of COT, exhibiting a daily repeated pattern especially in days when the TC had high intensities. Dunion et al. (2014) noted that the TC diurnal cycle signal is more pronounced in storms of

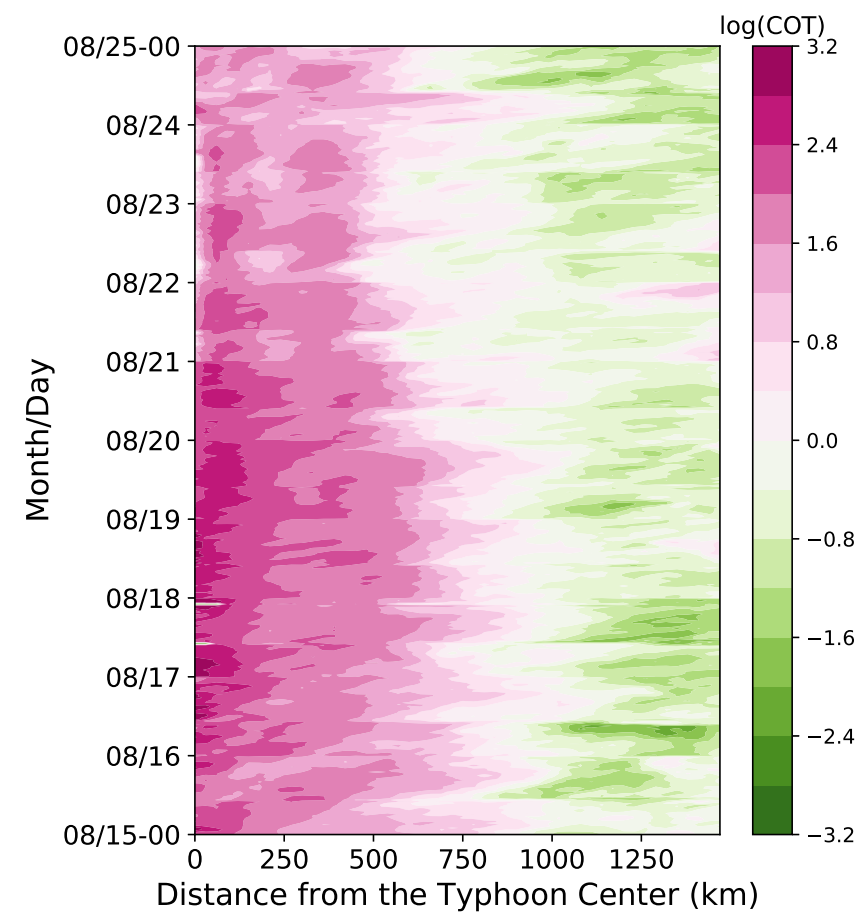

Fig. 2. Ten-day evolution of median $\log (\mathrm{COT})$ retrieved by ICAS with Himawari-8 observation from 0000 LST 17 August to 2400 LST 21 August. Clouds at all heights are included.
Saffir-Simpson category 2 ( $84 \mathrm{kt} / 155 \mathrm{~km}$ per hour) or higher. For better identification of the start and end points (both temporal and spatial) of the observed diurnal oscillation, we selected a 5-day period from Fig. 2 that covers 17-21 August when the intensity of Atsani reached its maximum (65-100 kt/120-185 km per hour), and then calculated the daily-mean radius-time distribution of median $\log (\mathrm{COT})$ as shown in Fig. 3. The high COT area started to propagate outward before noon $(\sim 0800 \mathrm{LST}-1200 \mathrm{LST})$ and persisted until 0400 LST next morning.

To investigate the underlying physical mechanisms of the diurnal pulse process shown in the COT field of TC Atsani, we split high cloud into three COT categories that approximately represent three different cloud types: cirrus $(\mathrm{Ci}$; $\mathrm{COT} \leq 1)$, cirrostratus $(\mathrm{Cs} ; 1<\mathrm{COT} \leq 6)$, and opaque high cloud $(\mathrm{OHC} ; \mathrm{COT}>6)$. Hereafter, the diurnal cycle will first be described in terms of the cloud fractional coverage, then the CTH. Figure 4 shows a 10 -day evolution of the fractional coverage of clouds within TC Atsani. The distribution of high-cloud fractional coverage indicates that the high clouds within Atsani were mainly composed of $\mathrm{OHC}$ and

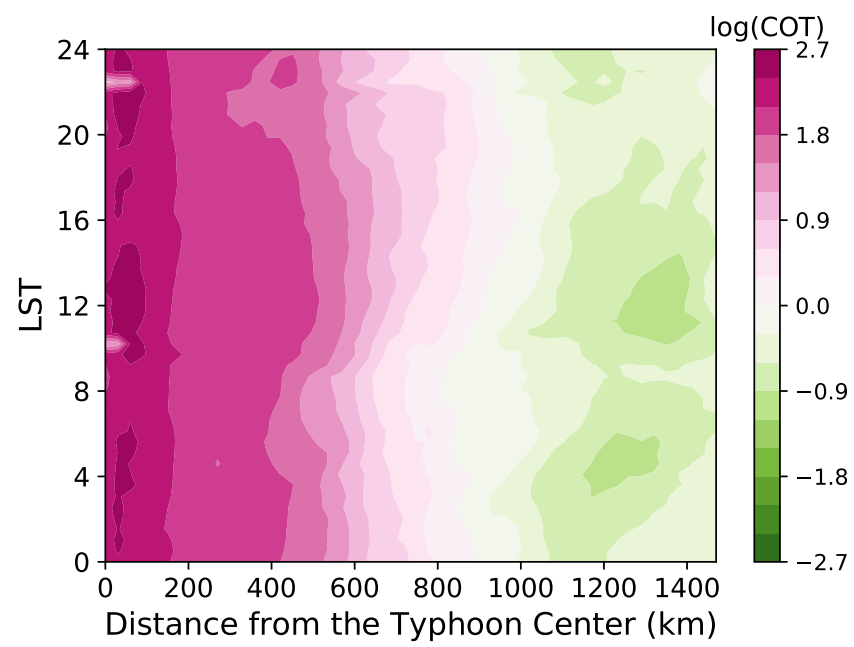

Fig. 3. Diurnal pattern of median $\log (\mathrm{COT})$ averaged over a five-day period of Fig. 2, from 0000 LST 17 August to 2400 LST 21 August.
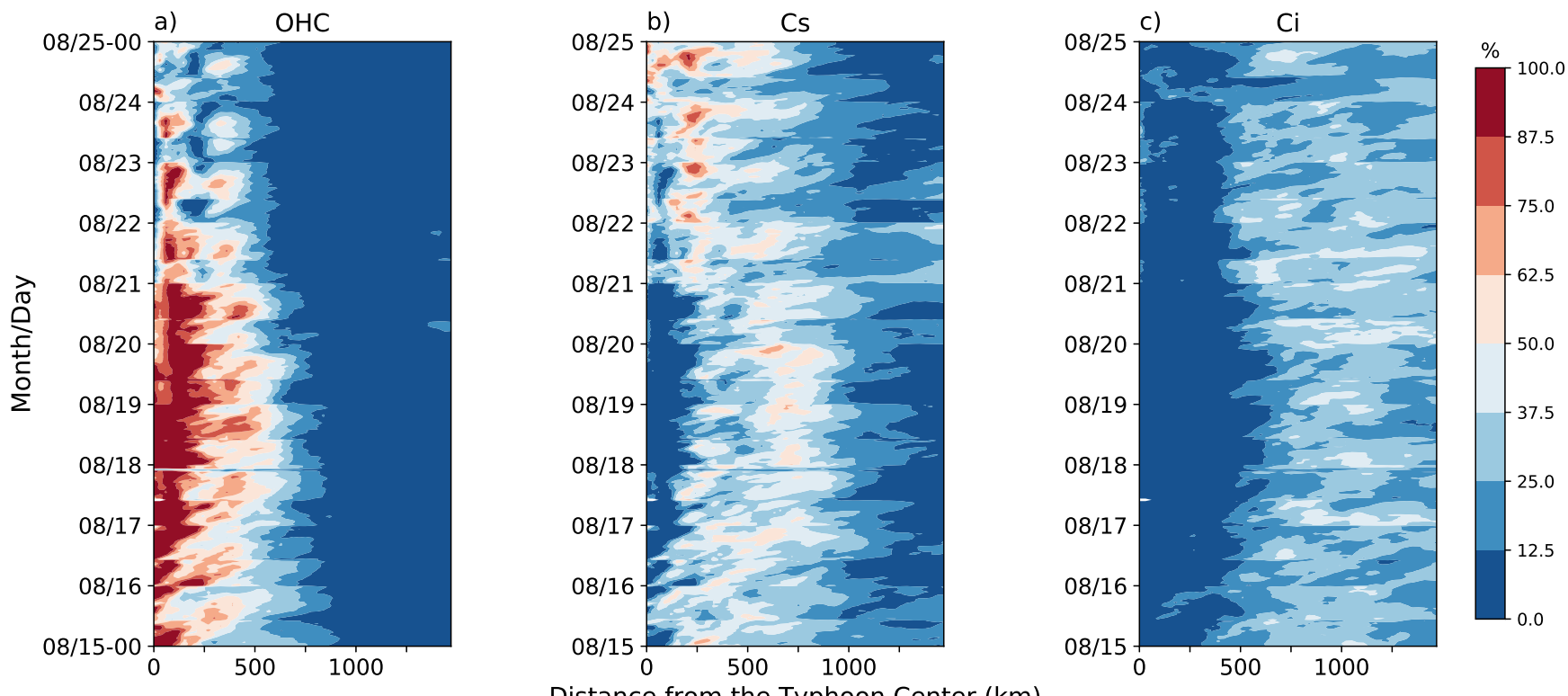

Distance from the Typhoon Center $(\mathrm{km})$

Fig. 4. Ten-day evolution of the high-cloud fraction retrieved by ICAS with Himawari-8 observation for (a) OHC, (b) Cs, and (c) Ci, respectively. The time period spans from 0000 LST 15 August to 2400 LST 24 August. 

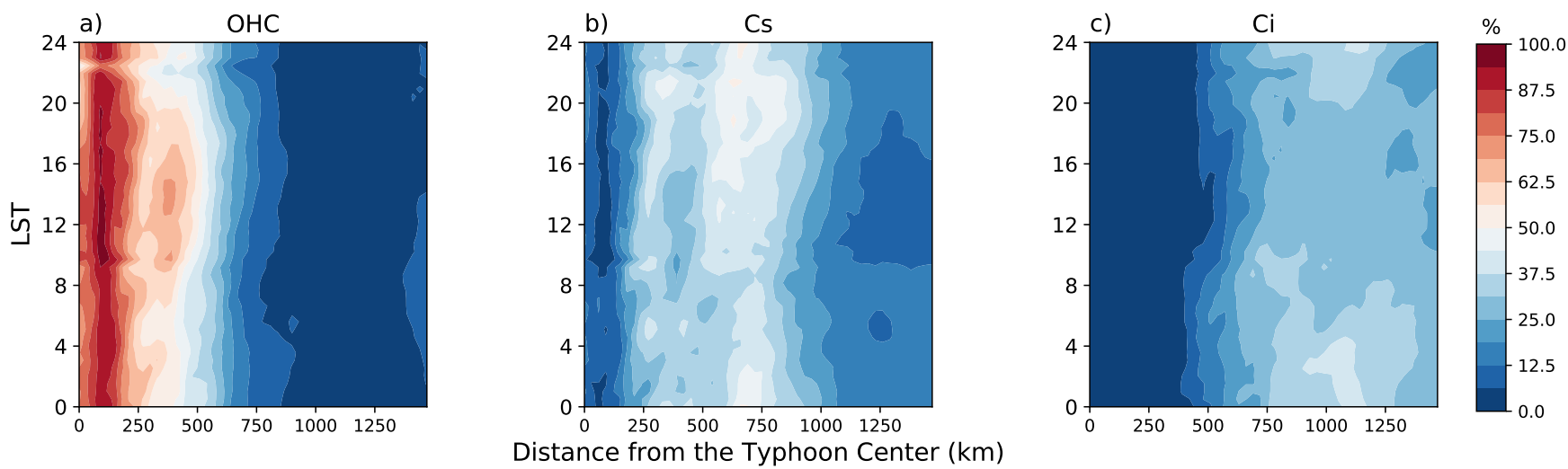

Fig. 5. Diurnal pattern of the high-cloud fraction averaged over a five-day period of Fig. 4, from 0000 LST 17 August to 2400 LST 21 August.
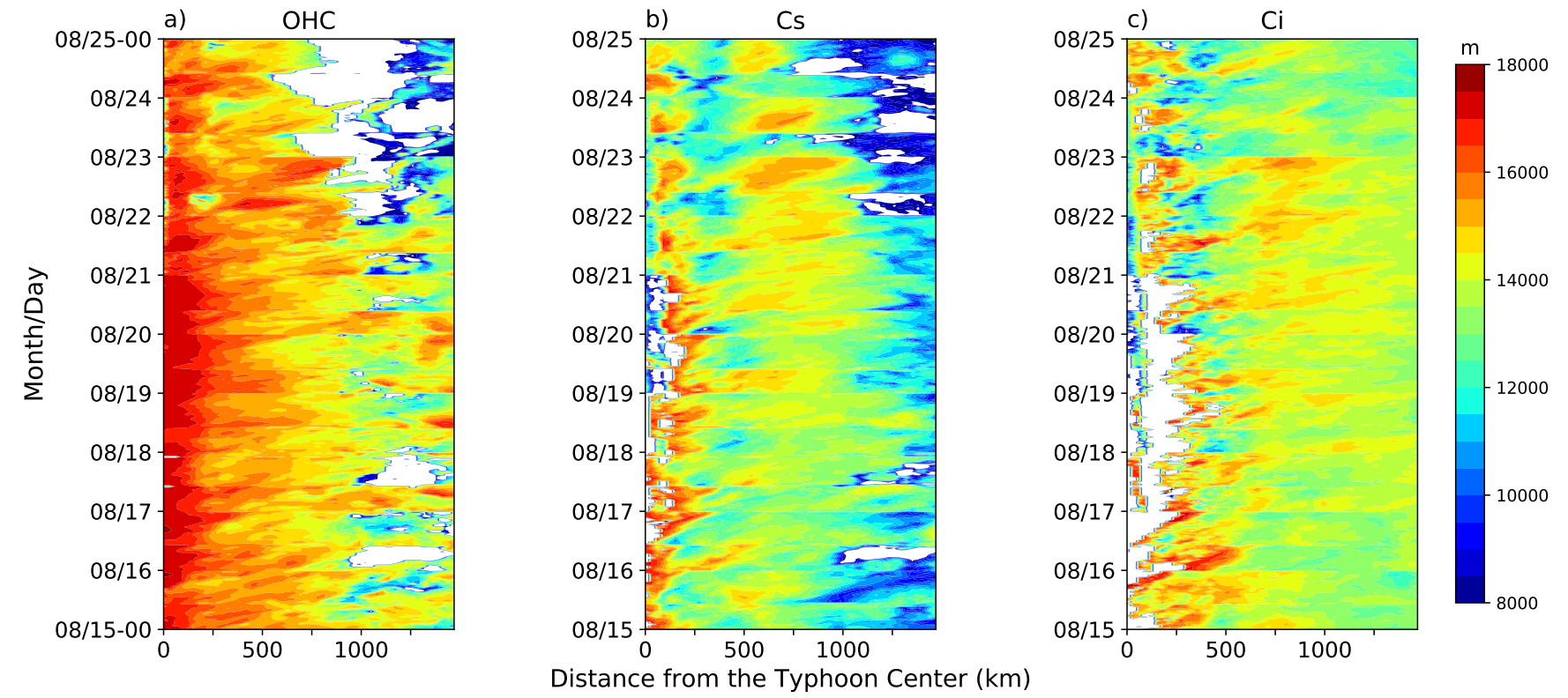

Fig. 6. Same as Fig. 4, but for median-CTH. Clouds with median-CTH lower than $8 \mathrm{~km}$ are masked out.

Cs, both of which tended to appear within a radius of $1000 \mathrm{~km}$ from the storm center. During the mature phase of Atsani, its inner-core region was almost totally occupied by $\mathrm{OHC}$, while $\mathrm{Cs}$ emerged around $200 \mathrm{~km}$ from the storm center, and $\mathrm{Ci}$ appeared around $500 \mathrm{~km}$ from the storm center.

The daily-mean patterns of cloudiness (calculated based on the selected 5-day period) for the three cloud types are shown in Fig. 5. The general fractional coverage of $\mathrm{OHC}$ and $\mathrm{Cs}$ started growing at solar noon and reached maximum in the afternoon. It gradually decreased from dawn until next morning (till $\sim 0800$ LST), consistent with the diurnal oscillation manifested in the COT field (Fig. 3). This radially evolving pattern of both the COT and cloud fraction is in phase with the amount of incoming solar radiation, which is the largest at solar noon. Similar results based on three cloud-top temperature thresholds are shown in Browner et al. (1977), that study noted an average maximum of areal coverage at 1700 LST.

The TC diurnal pulse evolution is more evident when we consider its stage-by-stage transition from one cloud type to another. In detail, the optically thick cloud with COT values larger than $6(\mathrm{OHC})$ peaked in areal extent at around 1300-1600 LST (Fig. $5 \mathrm{a})$, with the maximum cloud fraction appearing at around $100 \mathrm{~km}$ from the storm center. Shortly after that, the peak of cloud with COT values between 1 and 6 (Cs) appeared at 1800-2200 LST
(Fig. 5b), with the peripheral cloud reaching $1100-\mathrm{km}$ radius and the highest cloud amount locating between 500 and $750 \mathrm{~km}$ from the storm center. Afterwards, the pulse manifested itself in the clouds with COT values less than $1(\mathrm{Ci}$, Fig. 5c), in which the highest cloud fraction located between 800 and $1200 \mathrm{~km}$ from the storm center at around 0000-0400 LST, marking the end of the pulse.

Many previous studies have investigated the diurnal cycle of CTH by dividing the clouds into different heights according to satellite infrared brightness temperature, which serves as a proxy for cloud-top temperature. The current analysis is the first one utilizing the combination of CTH and COT directly retrieved from satellite-observed radiances. Figure 6 shows the 10-day evolution of median $\mathrm{CTH}$, in each storm-centered annulus within $1500 \mathrm{~km}$ from the storm center, for the three COT groups respectively. A pulse pattern similar to that in cloudiness appeared in the CTH field of the three cloud types: the pulse gradually transitioned from $\mathrm{OHC}$ to $\mathrm{Cs}$ and ultimately ended in Ci. This median CTH pulse predominately consisted of clouds higher than $15 \mathrm{~km}$.

From the 5-day averaged CTH pattern (Fig. 7), two peaks in the median CTH and the accompanying semidiurnal cycles are identified, as consistent with current consensus (Kossin 2002; Dunion et al. 2014; Haffke et al. 2015). The corresponding quantitative identifications of the $\mathrm{CTH}$ cycles on subdaily timescales 

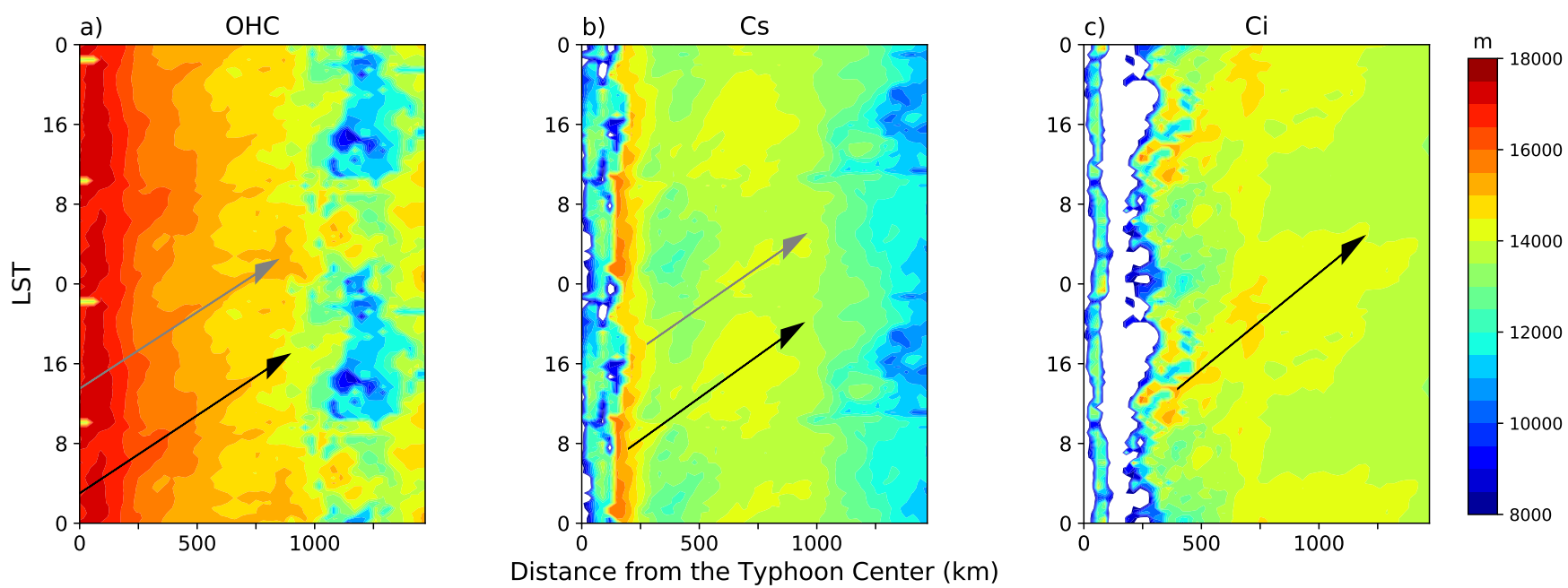

Fig. 7. Same as Fig. 5, but for the diurnal pattern of median-CTH. The daily average is shown in a 48-hour scale to include the complete patterns of two pulse processes. Black arrows indicate the morning-started diurnal pulse process, and gray arrows indicate the afternoon-started diurnal pulse process.

are shown in Fig. S2. One cycle started in the early morning (black arrow in Fig. 7a), at 0400-0700 LST, when cloud area was at a minimum (Fig. 5a), and the second (gray arrow in Fig. 7a) started in the sunset hours when the first cycle ended, nearly in concert with the maximum in cloud area (Fig. 5a). In the convective region $(\leq 1000 \mathrm{~km}$ from the storm center and COT $>1)$, those two semi-diurnal cycles alternately started in $\mathrm{OHC}$ and respectively spread to Cs, while the morning-started pulse seems to be stronger and continued to move outward till ended in $\mathrm{Ci}$ (black arrow in Fig. 7c). This "OHC-Cs-Ci" transition process exclusively manifested in the morning-started pulse and composed the main diurnal oscillation that is evident in Fig. 6. Kossin (2002) suggested that the semidiurnal oscillation may be driven by the physical connection between cold cloud tops and semidiurnal atmospheric tide. That study noted that the variation of local lapse rate indicates a semidiurnal cycle existing in tandem with the semidiurnal atmospheric tide. More recently, studies on the afternoon-started outflow of anvil clouds in tropical cylones (Ruppert and Klocke 2018; Ruppert and O'Neill 2019) suggested that this pulse process is due to the cloud-shortwave heating, which causes an increase in upper-level upward motion and hence the peak of anvil clouds during daytime.

After those two CTH pulses both ended at around 0400 LST (the black arrow in Fig. 7c and the gray arrow in Fig. 7b), the first pulse started a new cycle again. Based on the spatiotemporal pattern shown in Fig. 7, the first CTH pulse reached a radius of $200 \mathrm{~km}$ from the storm center at $\sim 0400-0800 \mathrm{LST}$, a radius of $300 \mathrm{~km}$ at $\sim 0800-1200 \mathrm{LST}$, and a radius of $400 \mathrm{~km}$ at $\sim 1200-$ 1500 LST. We estimate the diurnal pulse propagation speed to be $5-10 \mathrm{~m} / \mathrm{s}$, a value similar to that estimated by Dunion et al. (2014).

The temporal and spatial cycle of the median CTH pulse might also have important implications for the timing of Typhoon Atsani's inner-core convection and possibly its precipitation rate. For example, the first pulse that started in the early morning, at 0400-0800 LST, is consistent with the early-morning rainfall peak found in the organized deep convections over the tropical oceans, including the TCs (Bowman and Fowler 2015). For the afternoon peak in $\mathrm{CTH}$ field and its relationship with the rainfall variation within a TC system, future studies are required for better elucidation on their potential linkage.

Intriguingly, the morning-started pulse in median CTH field seems to direct the diurnal oscillation in cloud fractional coverage (Fig. 5). The morning-started CTH pulse (the black arrow in Fig. 7a) lost its convective characteristics as it moved away from the storm. When it ended in three cloud types respectively, the fractional coverage of these three cloud types reached maximums at the corresponding time and radius as well, forming a stepladder pattern as shown in the red shadings of Fig. 5a and the white shadings of Figs. 5b and 5c. This maximum-train further composed the pulse transition of cloudiness. To be specific, the first pulse of CTH started in early morning from the innermost core of the typhoon. For OHC, this pulse ended at around 1700 LST (the end of the black arrow in Fig. 7b), while for Cs the pulse ended at 1800-2000 LST (the end of the black arrow in Fig. 7b), which were exactly the time ranges when they had peaks in fractional coverage and areal extent (Figs. 5a and 5b). At around 1300$1500 \mathrm{LST}$, this $\mathrm{CTH}$ pulse transitioned to $\mathrm{Ci}$. It propagated to the radius of $1200 \mathrm{~km}$ and finally ended at $\sim 0000-0400$ LST when the fraction of $\mathrm{Ci}$ reached its maximum accordingly.

The underlying mechanism controlling the evolution of TC diurnal pulses can be summarized as follows. After cloud-top cooling (i.e., the lapse-rate mechanism) invigorated the nocturnal deep convection, a CTH pulse from the very high, thick clouds started in the early morning. Then at sunset, those high clouds (Cs) reached their furthest distance from the typhoon center, and the pulse ended in thin clouds $(\mathrm{Ci})$. Along with this outward expansion of cloud height and cloud fraction, there was a synchronous spreading of COT. The COT propagation reached a maximum radius at $\sim 2000$ LST when the Cs coverage and areal extent peaked.

\section{Conclusion}

We have presented a satellite-based examination on the diurnal pulses of clouds in Typhoon Atsani. By separating high clouds into three categories, our study complements previous findings with a transition process, manifested in both time and space, within a TC case. The cloud properties data set used in this study was retrieved by ICAS using observations from the Himawari-8 satellite. Here we analyzed cloud fraction, as well as CTH and COT. Our current study yields results consistent with those of previous studies, and at the same time provides perspectives on the joint cycle composed of different cloud properties that enriches the interpretation of diurnal pulses typical in tropical cyclones. We identified a prominent diurnal oscillation of cloudiness that explains a large variance in each cloud annulus. The pulse in fractional coverage approached a maximum and ended: in the late afternoon for $\mathrm{OHC}$, at around 1800-2200 LST for Cs, and at around 0000-0400 LST for Ci, respectively. This stepladder pattern was later found to exist in tandem with, and possibly to be directed by, the first pulse in CTH.

Two pulse processes in the $\mathrm{CTH}$ are identified: the first emerged in the early morning and seemed to dominate the diurnal 
cycle evident in the 10-day pattern, while the second pulse started at $\sim 1600$ LST and finished at $\sim 0400$ LST at a semidiurnal scale. Based on this pattern, we can infer that the afternoon peak likely acted as an energy supplement for the first pulse within the deep convective region, although it did not participate directly in the main joint-cycle. The joint cycle of radially outward spreading was co-presented by cloud fraction, $\mathrm{CTH}$, and COT. It was evident in the daytime, especially during the afternoon period. Along with the CTH pulse propagation, peaks of cloud fraction and COT moved outward accordingly and reached their maximum distance from the storm center when the CTH pulse ended.

Although the present study focuses on only one TC, the phase of diurnal oscillations identified here will not vary much between individual storms. A larger dataset consisting of multiple storms may help answer whether the obtained results can be applied to other TCs or not. Moreover, we note that Himawari-8 observes only cloud top (temperature, water vapor) and reflectivity. For a better understanding of the underlying mechanisms of the diurnal pulse processes and the possible co-variation between clouds and rainfall within a TC system, future studies are needed to verify the exact kind of convection that cloud types defined by COT represent.

\section{Acknowledgements}

The Himawari- 8 data used in the present study were obtained from the NICT Science Cloud at National Institute of Information and Communications Technology (NICT), Japan. This work was conducted as a part of the 1st Research Announcement on the Earth Observations of the Japan Aerospace Exploration Agency (JAXA) (PI No.: RA1R306).

Edited by: K. Cheung

\section{References}

Bain, C. L., G. Magnusdottir, P. Smyth, and H. Stern, 2010: Diurnal cycle of the intertropical convergence zone in the east Pacific. J. Geophys. Res., 115, D23116, doi:10.1029/2010 JD014835.

Bessho, K., K. Date, M. Hayashi, A. Ikeda, T. Imai, H. Inoue, Y. Kumagai, T. Miyakawa, H. Murata, T. Ohno, A. Okuyama, R. Oyama, Y. Sasaki, Y. Shimazu, K. Shimoji, Y. Sumida, M. Suzuki, H. Taniguchi, H. Tsuchiyama, D. Uesawa, H. Yokota, and R. Yoshida, 2016: An introduction to Himawari-8/9Japan's new-generation geostationary meteorological satellites. J. Meteor. Soc. Japan, 94, 151-183.

Bowman, K. P., and M. D. Fowler, 2015: The diurnal cycle of precipitation in tropical cyclones. J. Climate, 28, 5325-5334, doi:10.1175/JCLI-D-14-00804.1.

Browner, S. P., W. L. Woodley, and C. G. Griffith, 1977: Diurnal oscillation of cloudiness associated with tropical storms. Mon. Wea. Rev., 105, 856-864.

Chen, S., and R. A. Houze, 1997: Diurnal variation and life-cycle of deep convective systems over the tropical Pacific warm pool. Quart. J. Roy. Meteor. Soc., 123, 357-388.

Dunion, J. P., C. D. Thorncroft, and C. S. Velden, 2014: The trop- ical cyclone diurnal cycle of mature hurricanes. Mon. Wea. Rev., 142, 3900-3919.

Gelaro, R., W. McCarty, M. J. Suárez, R. Todling, A. Molod, L. Takacs, C. A. Randles, A. Darmenov, M. G. Bosilovich, R. Reichle, K. Wargan, L. Coy, R. Cullather, C. Draper, S. Akella, V. Buchard, A. Conaty, A. M. da Silva, W. Gu, G. Kim, R. Koster, R. Lucchesi, D. Merkova, J. E. Nielsen, G. Partyka, S. Pawson, W. Putman, M. Rienecker, S. D. Schubert, M. Sienkiewicz, and B. Zhao, 2017: The ModernEra Retrospective Analysis for Research and Applications, Version 2 (MERRA-2). J. Climate, 30, 5419-5454, doi: 10.1175/JCLI-D-16-0758.1.

Haffke, C., and G. Magnusdottir, 2015: Diurnal cycle of the South Pacific Convergence Zone in 30 years of satellite images. $J$. Geophys. Res. Atmos., 120, 9059-9070.

Holland, G. J., and R. T. Merrill, 1984: On the dynamics of tropical cyclone structural changes. Quart. J. Roy. Meteor. Soc., 110, 723-745.

Iwabuchi, H., M. Saito, Y. Tokoro, N. S. Putri, and M. Sekiguchi, 2016: Retrieval of radiative and microphysical properties of cloud from multispectral infrared measurements. Prog. Earth Planet. Sci., 3:32, Oct 21, doi:10.1186/s40645-0160108-3.

Iwabuchi, H., N. S. Putri, M. Saito, Y. Tokoro, M. Sekiguchi, P. Yang, and B. A. Baum, 2018: Cloud property retrieval from multiband infrared measurements by Himawari-8. $J$. Meteor. Soc. Japan, 96B, 27-42, doi:10.2151/jmsj.2018001.

Khatri, P., H. Iwabuchi, and M. Saito, 2018: Vertical profiles of ice cloud microphysical properties and their impacts on cloud retrieval using thermal infrared measurements. J. Geophys. Res. Atmos., 123, 5301-5319, doi:10.1029/2017JD028165.

Kossin, J. P., 2002: Daily hurricane variability inferred from GOES infrared imagery. Mon. Wea. Rev., 130, 2260-2270.

Kraus, E. B., 1963: The diurnal precipitation change over the sea. $J$. Atmos. Sci., 20, 551-556.

Lajoie, F. A., and I. J. Butterworth, 1984: Oscillation of high-level cirrus and heavy precipitation around Australian region tropical cyclones. Mon. Wea. Rev., 112, 535-544.

Muramatsu, T., 1983: Diurnal variations of satellite-measured TBB areal distribution and eye diameter of mature typhoons. $J$. Meteor. Soc. Japan, 61, 77-89.

Randall, D. A., Harshvardhan, and D. A. Dazlich, 1991: Diurnal variability of the hydrologic cycle in a general circulation model. J. Atmos. Sci., 48, 40-62.

Rodgers, C. D., 2000: Inverse Methods for Atmospheric Sounding: Theory and Practice. World Scientific, Singapore, $238 \mathrm{pp}$.

Ruppert, J. H., and D. Klocke, 2019: The two diurnal modes of tropical upward motion. Geophys. Res. Lett., 46, 2911-2921.

Ruppert, J. H., and M. E. O'Neill, 2019: Diurnal cloud and circulation changes in simulated tropical cyclones. Geophys. Res. Lett., 46, 502-511.

$\mathrm{Wu}$, Q., and Z. Ruan, 2016: Diurnal variations of the areas and temperatures in tropical cyclone clouds. Quart. J. Roy. Meteor. Soc., 142, 2788-2796.

Manuscript received 21 November 2018, accepted 13 May 2019 SOLA: https://www.jstage.jst.go.jp/browse/solal 